\title{
The Strategy Selection of Intelligent Basic Education in F County China Based on SWOT Quantitative Model
}

\author{
Wang Maolin and Lin Yong
}

\begin{abstract}
The intelligent education is entering a high growth path whose connotation in the information age has extended gradually for over ten years. As a strategy intelligent education is an innovative measure to integrate basic education into the era of knowledge economy. Based on the actual conditions of the informatization degree of basic education in F County, we analyzed the internal strengths and weaknesses, external opportunities and threats in the development of intelligent basic education in $F$ County according to the empirical research results. We used SWOT quantitative analysis model to spot the strategy point finding it locates in the region of diversified adjustment in the quadrant diagram of the intelligent basic education strategy. F County should adopt a positive growth strategy to promote the construction of smart campus, promote the research and application of education technology, promote the improvement of teachers' intelligent education accomplishment, achieve the development of students' intelligence, and promote the modernization of local basic education.
\end{abstract}

Index Terms - Intelligent education, strategy selection, basic education, SWOT quantitative model.

\section{INTRODUCTION}

Under the background of the fourth industrial revolution, new technologies such as AI, robot technology, quantum information technology and virtual reality have been emerging one after another. Undoubtedly, the influence brought by scientific and technological progress will permeate all aspects of society. Throughout history of the development of human education ecosystem, every reform in education is bound up with a breakthrough in science and technology. In this digital age, knowledge is a special kind of information, whose transmission mechanism "encoding spreading - decoding" [1] will profoundly change. And the "creative destruction" will happen to education ecological system. Along with the advancement of education modernization in China, intelligent education is endowed with new meaning - returning to the nature of education, developing the intelligence of kids on account of "education informatization 2.0", taking subversive education technology as innovation factor to achieve the change of education pattern and the reconstruction of ecological. The arrival of "education informatization 2.0" has inspired new energy to intelligent education in China. Intelligent basic education is one of the inevitable trends in the development of basic

Manuscript received November 16, 2019; revised March 2, 2020. This work was supported in part by the Research Center of Science and Education Strategy, Chongqing University under Grant 2019-CQ-YB-7, Institute of Educational Sciences of Chongqing under Grant 2018-00-050.

The authors are with Research Center of Science and Education Strategy, Chongqing, China (e-mail: 443966612@qq.com, linyong@cqu.edu.cn). education.

Intelligent basic education strategy is based on the principle of the law of children's development, and refers to use smart education technology to create a good smart campus environment for children, adopt smart education strategy to optimize education effect and improve education efficiency, construct smart evaluation system to promote the diversification and lifelong development of teachers, and finally achieve the development of children's wisdom and basic education informatization. At present, the development of intelligent basic education in China is still at initial stage. How to choose the development direction scientifically and reasonably is a prerequisite for the rapid development of basic intelligent education. Therefore, exploring the strategy selection of intelligent education combining with theoretical analysis and practical situation is greatly significant to promote the modernization of basic education in China.

\section{OVERVIEW OF THE DEVELOPMENT OF INTELLIGENT EDUCATION}

We took citespace software as the analysis tool, taking CNKI as the main data source, and accurately matching "subject $=$ intelligent education". By June 9, 2019, we had manually screened 1,425 valid literatures. By analyzing the results, as shown in Fig. 1, we found that the research on the theoretical level of intelligent education has gone through three development stages: Beginning phase, Evolution phase and Rapid developing phase.

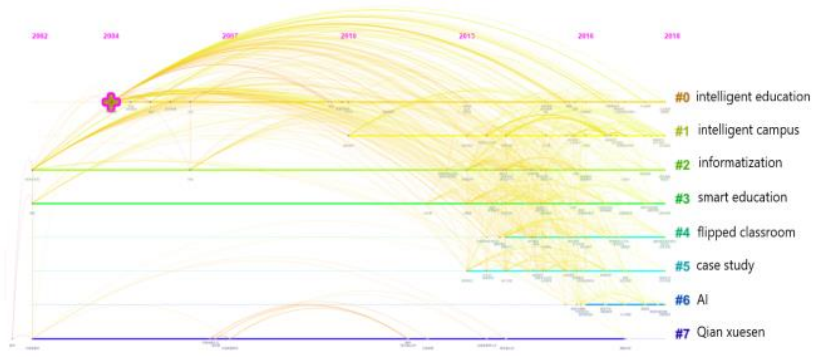

Fig. 1. Development chart of intelligent education.

\section{A. Beginning phase (2002-2010)}

In this period, education of China was under reforming, and the research on intelligent education mainly originates from the discussion of "science of wisdom in cyberspace" put forward by Mr. Qian Xuesen on the basis of modern science and technology. "Science of wisdom in cyberspace" advocates combining philosophy and the unity of science and technology, synthesizing to obtain wisdom $\left[{ }^{2}\right]$. Huang Lifeng connected "science of wisdom in cyberspace" study with education informatization and believed that the core of 
education informatization lies in the integration of information technology and teaching. In the research of this stage, most scholars in China analyzed and demonstrated "knowledge, education and wisdom education", "source of wisdom education" and "wisdom of teachers" from the perspective of philosophy and concept $\left[{ }^{3}\right]$, or interpreted wisdom education from the perspective of "wisdom" and "wisdom cultivation" in reviewing the education ideas of various educational masters $\left[{ }^{4}\right]$. Discussions on "smart education" or "intelligent education" abroad originated from the concept of "smart planet" first proposed by CEO of IBM in 2008. However, the research on smart education at this stage was still limited to the development of "intelligent technology".

\section{B. Evolution Phase (2011-2015)}

During the 5 years, research on intelligent education overseas increased year by year, and began to rise to the national strategy level. The United States has issued two national educational technology plans Transforming American Education: Technology-driven Learning and Learning for the Future, which propose to support the construction of an information-based smart education environment and emphasize the comprehensive reform of the education system. In 2006, Singapore began to implement Intelligent Nation 2015 Plan. Intelligent education played an important role in cultivating citizens in the future information society, developing citizens' lifelong learning ability, and maintaining the competitiveness of citizens and the country . South Korea guaranteed the implementation of intelligent education strategy from formulating relevant laws and regulations. At the same time, it attached importance to eliminating the negative impact of information technology on education, and tried to overcome the possible obstacles to the implementation of intelligent education strategy $\left[^{5}\right]$.

At this stage, the center of education modernization in China began to turn to education informatization, and the researches on intelligent education in China influenced by "smart education" overseas. Papers related to education informatization such as "Internet +", "big data", "smart education environment" and "information technology" sprang up like bamboo after a spring rain. Zhu and He's research Intelligent Education: A New Realm of Educational Informationization $\left[{ }^{6}\right]$ is one of the representative studies of this stage. They explored the origin of the connotation of intelligent education and systematically sorts out the existing research progress of intelligent education. 2013 is the year of big data. With the advent of the era of big data, the reform of intelligent education was gaining momentum. Zhu and Shen [7] proposed that learning analysis provides a scientific basis for the improvement of teaching and is an important pillar of intelligent education, and discussed the application of big data in the field of education technology and proposed the personalized adaptive learning system, a new education technology paradigm based on big data [8]. In 2015, the "Internet + " project was first proposed in the government work report, which made more and more intelligent education actions entering the market and subverting the traditional organizational form of education. The researches on new education models such as micro-class and flipped classroom were also gradually deepened. In this period, Chen Lin [9], Zhu Zhiting and other researchers conducted in-depth studies on the construction of intelligent education system based on big data, "Internet +" and other new generation information technologies.

\section{Rapid Developing Phase (2016-Now)}

2016 years is the year that artificial intelligence began to impinge on people's life overall. From Alpha Go to driverless cars, from American Presidential Election to the quantum computer, every focus-related event was connected with artificial intelligence. The breakthrough of artificial intelligence technology in 2016 also brought rapid development to intelligent education. The researches on intelligent education began to integrated with "deep learning", "adaptive learning", "machine learning" and other key areas of artificial intelligence. It is proposed in the paper Educational Application and Innovation Exploration of Machine Learning from the Perspective of Artificial Intelligence [10], that intelligent education should be integrated with machine learning, which should be applied to support technological innovation of intelligent environment and method innovation of intelligent didactics. With the application of artificial intelligence in the actual teaching activities, researches about the smart education environment, such as virtual reality and augmented reality technology gradually increased. "Audio-Visual Education in China" set up a special report on the issue in 2017 , virtual reality and augmented reality technology application in education conducted fruitful exploration. In March 2018, the Third China-U.S. Intelligent Education Conference was held in Beijing international conference center, and the conference's report focused on artificial intelligence 2.0 and educational informatization 2.0 [11]. The Horizon Report [12] released by the New Media Alliance of the United States identified six major challenges that will impact the application of technology, four of which are directly related to smart education technology: real learning experience, improving digital literacy, adapting organizational design to the future, and promoting digital equity. And they predicted there are six technologies most likely to drive education technology planning and decision-making in the next 5 years. Among them, learning analysis and maker space are expected to be widely used in 1-2 years. Adaptive learning technology and artificial intelligence are expected to be widely applied in 2-3 years. Mixed reality, robots are likely to go mainstream in the next 4-5 years.

In general, the research on intelligent education has accumulated rich achievements, and many researchers have analyzed the concept and characteristics of intelligent education, and there are many studies from the technical point of view. However, it is still a vacancy that to integrate intelligent education with basic education, and the combination between theory and practice still needs improvement.

III. SWOT QUANTITATIVE ANALYSIS MODEL FOR STRATEGy SELECTION OF INTELLIGENT EDUCATION 


\section{A. Implementation Steps of the Model}

On the basis of traditional SWOT analysis model, scholars have made a series of improvements to this model by adopting some quantitative analysis methods. On account of the current situation and actual conditions of basic education in F County, the SWOT quantitative model based on the method combining qualitative methods with quantitative ones proposed by Huang Rongbing and Li Yuhui [13] is adopted to analyze the strategy selection of intelligent basic education in F County. The implementation steps of the model are shown in Fig. 2.

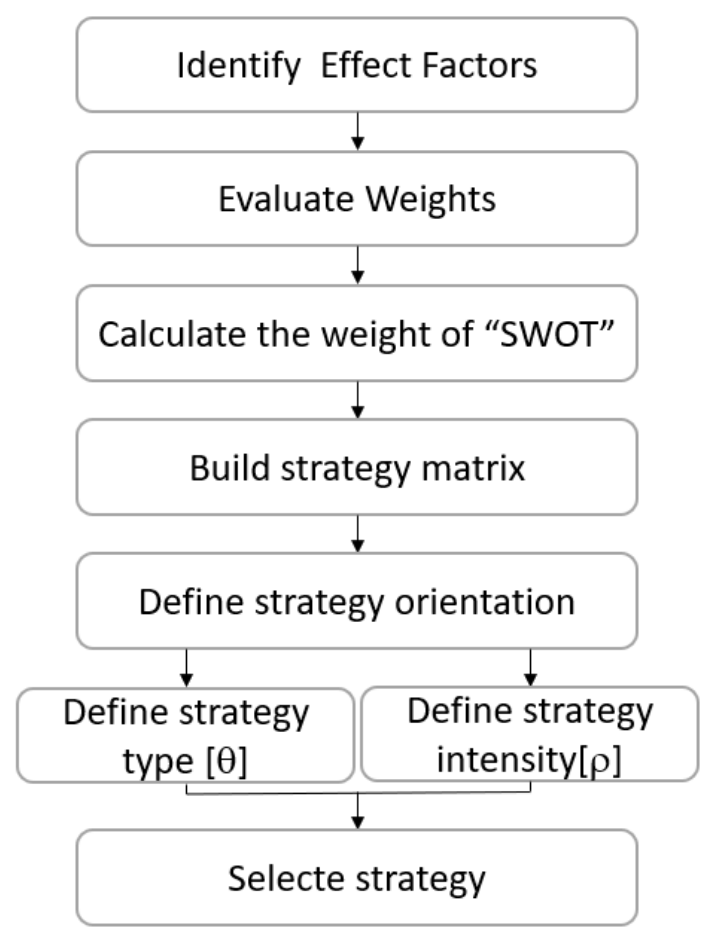

Fig. 2. Flow chart of SWOT quantitative analysis model.

\section{B. Azimuth and Matrix of the Intelligent Basic Education Strategy}

TABLE I: SWOT QUANTITATIVE ANALYSIS STRATEGY QUADRANTS

\begin{tabular}{|c|c|c|c|c|c|c|c|}
\hline \multicolumn{2}{|c|}{ Quadrant 1} & \multicolumn{2}{|c|}{ Quadrant 2} & \multicolumn{2}{|c|}{ Quadrant 3} & \multicolumn{2}{|c|}{ Quadrant 4} \\
\hline \multirow{2}{*}{\multicolumn{2}{|c|}{ Pioneering strategic area }} & \multirow{2}{*}{\multicolumn{2}{|c|}{ Torsion strategic area }} & \multirow{2}{*}{\multicolumn{2}{|c|}{$\begin{array}{l}\text { Conservative strategic area } \\
\text { (WT) }\end{array}$}} & \multirow{2}{*}{\multicolumn{2}{|c|}{$\begin{array}{l}\text { Diversification strategic area } \\
\text { (ST) }\end{array}$}} \\
\hline & & & & & & & \\
\hline Type & Azimuth & Type & Azimuth & Type & Azimuth & Type & Azimuth \\
\hline Strength-based & $\left(0, \frac{\pi}{4}\right)$ & Enterprising & $\left(\frac{\pi}{2}, \frac{3 \pi}{4}\right)$ & Retreating & $\left(\pi, \frac{5 \pi}{4}\right)$ & Enterprising & $\left(\frac{3 \pi}{2}, \frac{\pi}{4}\right)$ \\
\hline Opportunistic & $\left(\frac{\pi}{4}, \frac{\pi}{2}\right)$ & Adjusting & $\left(\frac{3 \pi}{4}, \pi\right)$ & Avoidant & $\left(\frac{5 \pi}{4}, \frac{3 \pi}{2}\right)$ & Adjusting & $\left(\frac{\pi \pi}{4}, 2 \pi\right)$ \\
\hline
\end{tabular}

According to the SWOT analysis matrix and the quadrant position of the strategy azimuth, the four strategy types are respectively located in the four quadrants of the coordinate system. The first quadrant is the pioneering strategy area (SO), and the strategy type of this area is subdivided into Strength-based type and Opportunistic type according to the size of azimuth Angle. The second quadrant is the torsion strategy area (WO), which can be subdivided into the enterprising type and the adjusting type. The third quadrant is conservative strategy area (WT), and the strategy types of this region can be divided into retreating type and avoidant type according to azimuth. The fourth quadrant is the diversification strategy area (ST), which can be divided into the aggressive type and the adjusted type. The strategy types is shown in Table I

\section{ANALYSIS ON THE ELEMENTS OF THE DEVELOPMENT OF INTELLIGENT BASIC EDUCATION F COUNTY}

\section{A. Internal Strengths}

S1: The overall quality of teachers is relatively high. The proportion of elementary education teachers in F County received higher education was $71.1 \%$. Teachers had strong learning ability and basic modern teaching ability. They could use multimedia equipment, various office software and mobile APP to assist teaching in classroom teaching. S2: The management department attached great importance to the integration of intelligent education and basic education. At that time, the concept of "intelligent" has been integrated into all aspects of social life. The education department in $\mathrm{F}$ County had organized academic discussions and practical activities about relevant subjects. S3: Teachers, students and parents were highly motivated. We found $80 \%$ of teachers and parents in $\mathrm{F}$ County holding a positive attitude towards the reform of "intelligent education" by interview. They believed that "intelligent education" can promote children's comprehensive development and stimulate their interest in learning. Meanwhile, through case teaching, it was found that children who received "intelligent education" show stronger participation and enthusiasm in class. S4: public teaching resource was share between schools by open platform. There was a network service platform in F County based on the Sakai open source teaching platform. Relevant learning resources were regularly released on the platform, and related activities to promote the development of teacher digitization also were organized by the platform.

\section{B. Internal Weaknesses}

W1: Available funds were insufficient. There was a certain amount of investment for basic education in F County, but the construction of intelligent education needs high level educational technological facilities, making the funds is slightly insufficient. W2: Teachers' accomplishments of intelligent education needed to be improved. Although possessing abilities of information-based teaching and the educational concept, most teachers are unfamiliar with intelligent education and lack of understanding that how to operate intelligent educational technology and the theory of intelligent education. W3: The construction of smart campus was not complete. The construction of the intelligent education ecosystem should be based on the smart environment. The overall informatization level of basic education and teaching facilities in F County was not high, and there were big gaps between schools. The construction of "cloud network" as the core of smart campus was still in the initial stage. W4: Intelligent education management system had not been established. The intelligent education management system in F County had not been established, and the data's utilization and mining were not sufficient. It was difficult to conduct dynamic and sustainable management of teachers and students, which was not conform to the concept of smart education. 


\section{External Opportunities}

O1: The policy environment supported the development of smart education. Education Informatization 2.0 Action Plan was formally put forward on April 13, 2018, which repeatedly mentioned the construction of intelligent education, emphasizing the redesign of learning space, open education resources diffusion and other important means of intelligent education. O2: Intelligent education can promote the deepening cooperation among the government, schools, teachers and parents and the development of children. Multi-participation is an important part of the platform management system of intelligent education. O3: The cognitive structure of contemporary children calls for intelligent education. Digital natives' learning style, behaviour pattern, knowledge organization, emotional experience and expression, and self-understanding are fundamentally different from "digital immigrants" [14]. O4: The informatization reform of basic education was carried out in the whole city. On April 2, 2019, the Ministry of Education issued the Opinions on the Implementation of Project 2.0 to Improve the Information Technology Application Ability of Primary and Secondary School Teachers Nationwide, aiming to promote the ability of information technology application of primary and secondary school teachers nationwide (including kindergartens, ordinary primary and secondary schools and secondary vocational schools). In response to national policy, F County put the current basic education reform into practice in the whole city, which provided necessary support to intelligent education.

\section{External Threats}

T1: There was no sustainable intelligent education funding guarantee mechanism. Intelligent education is a comprehensive reform of the education ecosystem in this information age. It takes a long time to build the software foundation from the information hardware equipment to the education idea and teaching method. However, at present, there was a lack of sustainable funding guarantee mechanism for intelligent education countrywide, which hindered the development of intelligent education. T2: There was a lack of complete intelligent education evaluation system and supervision mechanism. The development of intelligent education in China was still in its infancy, and an incentive mechanism have not been formed. The absence of supervision mechanism for the construction of intelligent education directly impaired the quality of $\mathrm{F}$ County's development of intelligent education. T3: There were few successful experiences to learn from. The intelligent education was still in the early stage of research, and its application and practice at all levels of education was still in the process of exploration. T4: The application of educational technology is complicated, and it is difficult for education technology to keep up with the speed of technology upgrading.

\section{QuANTITATIVE ANALYSIS ON STRATEGy SELECTION OF INTELLIGENT BASIC EDUCATION IN F COUNTY}

\section{A. Evaluate Weights of Factors}

Firstly, we designed the SWOT factor expert evaluation table, as shown in Table II. The estimated influence value of each factor represents the influence strength of this factor considered by experts. The level is designed from -4 to +4 . The positive value represents the advantage and opportunity factors, and the negative value represents the disadvantage and threat factors. With larger absolute value comes greater influence, and vice versa. The estimated probability of existence of each factor $(\%)$ represents the probability that experts thought this factor may exist. The level is designed from $0 \%$ to $100 \%$.

TABLE II: EXPERT EVALUATION TABLE

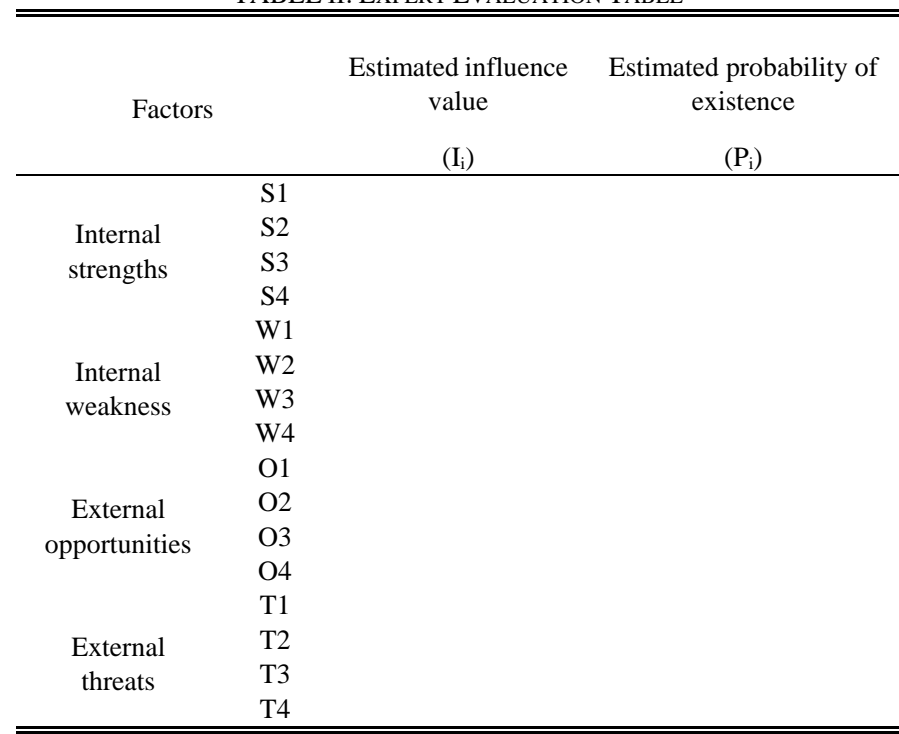

We selected experts according to the following three principles. 1) Samples should contain front-line managers who have a solid theoretical foundation, rich practical experience and a good understanding of the development history and current situation of F County; 2) Samples should contain representative experts engaged in the theoretical and strategy research of intelligent education; 3) The number of experts is controlled between 20 and 30. Therefore, we finally selected 5 experts in the field of basic education development research, 5 experts who were in charge of Education Informatization Development Management of $F$ County, 5 experts who were in the Development and Planning Department of $F$ County, 5 front-line teacher. A total of 20 people served as the expert team of this study and evaluated the indicators. In the process of expert assessment, the experts also put forward suggestions for each index. We further revised the expert rating table according to these suggestions.

\section{B. Build Strategy Matrix}

The magnitude calculation formulas of each strategy factor are as follows. The calculation results are shown In Table III.

$$
\begin{gathered}
S_{i}=I_{i} \times P_{i}(i=1,2, \ldots, n) \\
W_{i}=I_{i} \times P_{i}(i=1,2, \ldots, n)
\end{gathered}
$$




$$
\begin{gathered}
O_{o}=I_{o} \times P_{o}(o=1,2, \ldots, n) \\
T_{t}=I_{t} \times P_{t}(t=1,2, \ldots, n) \\
S=\sum S_{i} / n \\
W=\sum W_{\mathrm{i}} / n \\
O=\sum O_{\mathrm{i}} / n \\
T=\sum T_{\mathrm{i}} / n
\end{gathered}
$$

TABLE III: EXPERT SCORING RESULTS

\begin{tabular}{lcccc}
\hline \hline FACTORS & $\mathrm{P}(\%)$ & $\mathrm{I}$ & $\begin{array}{c}\text { MAGNITUDE OF } \\
\text { EACH FACTOR }\end{array}$ & $\begin{array}{c}\text { TOTAL } \\
\text { MAGNITUDE }\end{array}$ \\
\hline S1 & 80 & 3.8 & 3.06 & 2.97 \\
S2 & 87.5 & 3.5 & 3.06 & \\
S3 & 71 & 3.8 & 2.7 & \\
S4 & 80 & 3.8 & 3.04 & -2.53 \\
W1 & 82 & -3.5 & -2.87 & \\
W2 & 74 & -3.2 & -2.37 & \\
W3 & 87 & -2.8 & -2.47 & \\
W4 & 80 & -3 & -2.4 & \\
O1 & 87 & 3 & 2.62 & \\
O2 & 84 & 3.5 & 2.94 & -2.82 \\
O3 & 81 & 2.8 & 2.27 & \\
O4 & 81 & 3.8 & 3.08 & \\
T1 & 80 & -4 & -3.6 & \\
T2 & 78 & 3 & -2.34 & \\
T3 & 84 & 3.5 & -2.94 & \\
T4 & 80 & 3 & -2.4 & \\
\hline \hline
\end{tabular}

We constructed a four - dimensional matrix with SWOT strength as each half - axis. In the matrix, the corresponding points of $\mathrm{S}$ denoting total strength, W denoting total weakness, $\mathrm{O}$ denoting total opportunity and $\mathrm{T}$ denoting total threat were respectively found: S1, W1, O1 and T1. By connecting the four points with line, the strategy quadrilateral figure S1W1O1T1 could be obtained, as shown in Fig. 3.

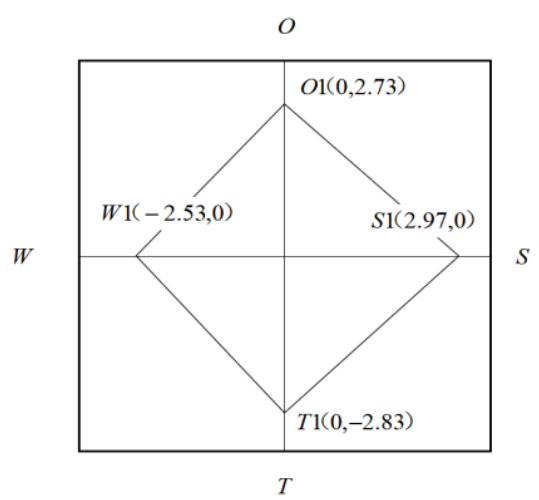

Fig. 3. Strategy quadrilateral of intelligent education.

\section{Calculate Strategy Azimuth Angle ( $\theta)$ and Strategy Intensity Coefficient $(\rho)$}

According to strategy quadrilateral S1W1O1T1, we can calculate the center of gravity coordinate $\mathrm{P}(\mathrm{x}, \mathrm{y})$, which is the basis to determine the strategy selection of intelligent basic education in F County. The coordinate calculation formula is:

$$
P(x, y)=\left(\sum x_{i} / 4, \sum y_{i} / 4\right)
$$

According to the calculation result, the coordinate of the strategy selection of intelligent education on basic education stage in F County is:

$$
P(x, y) \approx(0.11,-0.13)
$$

According to the center of gravity coordinates, we calculated $\theta$ and got $\tan \theta \approx-1.18$, obtained strategy azimuth $\theta$ $\approx 5.4$ by using the inverse trigonometry function, which is confirmed locating in the fourth quadrant.

In the process of selecting the type of development strategy, the strategy intensity should also be considered. Strategy intensity includes positive intensity and negative intensity. The positive intensity is the result of the combined action of internal advantages and external opportunities, which is denoted as U. On the contrary, its negative strength is the result of the combination of the internal weakness and external threat, which is denoted as V. Its calculation formula is shown below. By calculation, we got $\mathrm{U} \approx 8.11$; $\mathrm{V} \approx 7.16$.

$$
\begin{aligned}
& U=S \times O \\
& V=W \times T \\
& \rho=U /(U+V)
\end{aligned}
$$

By considering the positive strength and negative strength comprehensively, we can calculate the strategy strength coefficient as the basis to judge the development trend of intelligent education on the basic education stage in F County. Value of strategy intensity coefficient $(0<\rho<1)$ reflects the implementation intensity of strategy type. According to the formula, with the increase of $U$ value, the strategy strength coefficient increases, indicating that the strategy strength increases. On the contrary, with the increase of $\mathrm{V}$ value, the strategy strength coefficient decreases, indicating that the strategy strength is weakened. When $\rho \geq 0.5$, an active strategy should be taken, when $\rho<0.5$, a conservative strategy should be taken. According to the results, $(5.4,0.5)$ is the strategy positioning of the orientation diagram of strategy type and strategy intensity of F County, which is denoted as P point.

\section{Strategy Selection of Intelligent Basic Education in $f$ County}

The strategy positioning of $\mathrm{P}$ point of intelligent basic education strategy in F County is shown in Fig. 4. To develop intelligent education in F County, the education sector should 
adopt the strategy of adjustment and give full play to its own advantages to resist external threats. At the same time, due to the strategy intensity coefficient $\rho \geq 0.5$, a positive growth strategy should be adopted.

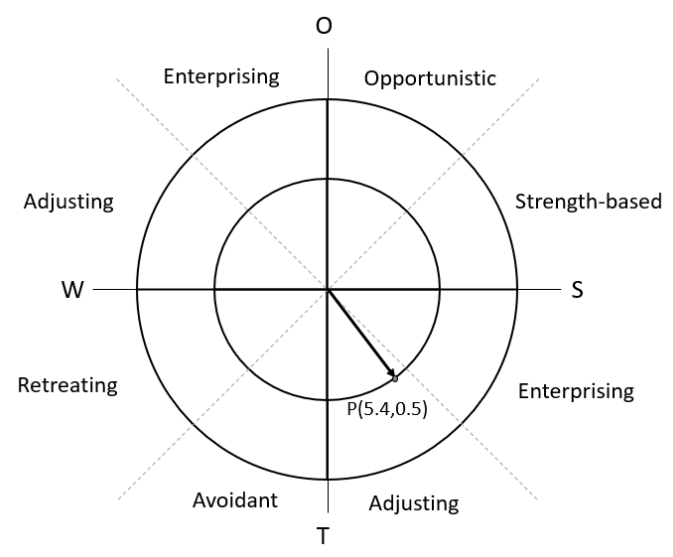

Fig. 4. Matrix of strategy selection of intelligent basic education in $\mathrm{f}$ County.

\section{PATH to APPLy INTELLIGENT EdUCATION TO THE BASIC EDUCATION IN F COUNTY}

\section{A. Making Use of Policy and Environmental Advantages to Promote the Construction of Smart Campus}

F County should actively seize the opportunity that intelligent education research is up-surging, and artificial intelligence has invaded into each social area, give full play to the policy advantages, make full use of the opportunity of basic education reform and "smart city" environmental construction resources in the whole city, and further improve the hardware environment level of intelligent basic education, and bring about the comprehensive improvement of the overall configuration level of smart education equipment .

\section{B. Creating a Transforming Environment to Improve Teachers' Intelligence Educational Accomplishment}

F County should create teaching reform environment, use educational technology, carry out relevant teaching and research activities, to improve teachers' theoretical understanding of intelligent education, improve teachers' application of intelligent educational technology and educational method with the impact of informational technology on the teaching field. They should also encourage teachers to apply intelligent education to carry out subject teaching activities, conduct diversified evaluate teachers through competitional activities and incentive systems, encourage teachers to carry out mixed and inquisitive teaching activities, and achieve teachers' sustainable career development and growth of educational wisdom through the development of intelligent educational activities.

\section{CONFLICT OF INTEREST}

The authors declare no conflict of interest. All authors had approved the final version.

\section{AUTHOR CONTRIBUTIONS}

Wang Maolin conducted the research, analyzed the data, and wrote the paper.
Prof. Lin directed the revision of the paper.

\section{REFERENCES}

[1] G. Wenge, "The motivation of educational change: The influence of media technology," Educational Research, vol. 39, no. 4, pp. 32-39, Apr. 12018.

[2] Q. Xuemin, "On Qian Xuesen's theory of Metasynthetic wisdom," Journal of Capital Normal University (Social Science Edition), vol. 9, no. 3, pp. 11-23, March 2001.

[3] T. Huisheng, "Educational wisdom and intelligent teachers," Educational Research, vol. 26, no. 2, pp. 56-57, Feb. 2005.

[4] A. H. Johnson, "Psychology of Alfred north whitehead," Journal of General Psychology, vol. 32, no. 2, pp. 175-212, Apr. 1945.

[5] C. Yaohua and Y. Xianmin, "Strategies of external smart education and the enlightenment," Modern Educational Technology, vol. 24, no. 10, pp. 5-11, Oct. 2014.

[6] Z. Zhiting and H. Bin, "Intelligent education: A new realm of educational informationization," E-Education Research, vol. 33, no. 12, pp. 5-13, Dec. 2012.

[7] Z. Zhiting and S. Demei, "Learning analysis: The scientific power of intelligent education," E-Education Research, vol. 34, no. 5, pp. 5-12, May. 2013.

[8] Z. Zhiting and S. Demei, "New paradigm of education technology research based on big data," E-Education Research, vol. 34, no. 10, pp 2-13, Oct. 2013.

[9] C. Lin and W. Yunwu, "Research on micro class design for intelligence education," Educational Research, vol. 36, no. 3, pp. 127-130, Mar. 2015.

[10] Y. Minghua1, F. Xiang, and Z. Zhiting, "The educational applications and innovative explorations of machine learning in the view of artificial intelligence," Journal of Distance Education, vol. 35, no. 3, pp. 11-21, Mar. 2017.

[11] China Institute of Education and Social Development, "The third china-U.S. Intelligent education conference focuses on artificial intelligence 2.0 and educational informatization 2.0," Journal of Educational Studies, vol. 14. no. 2, Feb. 2018.

[12] L. Yan and Y. Jiajia. "Hot spots and Trends in technology application of higher education: A review of ten years' horizon report (higher education edition)," Open Education Research, vol. 24, no. 6, pp. 12-28, Jun. 2018.

[13] H. Rongbing and L. Yuhui, "The SWOT quantitative model based on the polar coordinate system and its application research," Science Research Management, vol. 29, no.1, pp.179-187, Jan. 2008.

[14] M. Prensky, "Digital natives, digital immigrants part 2: Do they really think differently?" On the Horizon, vol. 9, no. 6, pp. 1-6, May 2001.

Copyright $\odot 2020$ by the authors. This is an open access article distributed under the Creative Commons Attribution License which permits unrestricted use, distribution, and reproduction in any medium, provided the original work is properly cited (CC BY 4.0).

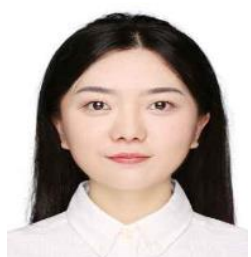

Wang Maolin was born in Zigong city, Sichuan province, China in Oct. 1995. She is doing her master of higher education in Chongqing University majoring in educational technology and educational management. She had been to City University of Malaysia for summer visiting, and had worked as an intern researcher in Chongqing Institute of Educational Sciences.

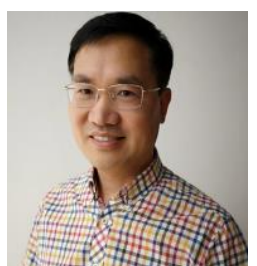

Lin Yong is a professor at School of Public Administration, Chongqing University; he works as the deputy director at Office of Chongqing Research Institute of China Engineering Science and Technology Development Strategy; he is also the deputy director of Chongqing University Engineering Science and Education Strategy Research Center. He received his Ph.D. in economics at Faculty of Economics and Management, Chongqing University. His researches focus mainly in education strategy and development. 